\title{
Analyze the effect of process parameters on the mechanical and metallurgical properties of composite AA6063/WC fabricated by friction stir processing
}

\author{
Gurpreet Singh \\ Department of Mechanical Engineering \\ Chandigarh Engineering College, Landran, Punjab, India \\ Inderjeet Singh \\ Department of Mechanical Engineering \\ Chandigarh Engineering College, Landran, Punjab, India
}

\begin{abstract}
AA6063 has good surface finishing, high corrosion, and resistance, is readily suited to processing and can be easily anodized, has high strength to weight ratio but low hardness and wear resistance properties. Friction stir processing is a novel technique of changing the properties of a metal through intense, localized plastic deformation. Frictions stir processing used in casting, powder metallurgy and surface modification. In the present research, a metal matrix composite was fabricated by using AA6063 alloy as the base metal. Tungsten carbide particles with 5 um particle size were added reinforcement. Tungsten carbide particles packed in series holes of diameter $2 \mathrm{~mm}$ and depth $3.5 \mathrm{~mm}$. A single pass FSP was carried out using constant tool rotational speed of $1500 \mathrm{rpm}$ and variable transverse speed of 30 $\mathrm{mm} / \mathrm{min}, 40 \mathrm{~mm} / \mathrm{min}$ and $50 \mathrm{~mm} / \mathrm{min}$. A tool made of high carbon high chromium steel, having a two different pin profiles cylindrical left hand threaded and square tool pin were used. Tool shoulder diameter and length of tool pin were $20 \mathrm{~mm}$ and $4 \mathrm{~mm}$ respectively. The side of square tool pin were $4 \mathrm{~mm}$. The mechanical and metallurgical properties of composite material fabricated by FSP were investigated. The results were compared with the properties of base metal. The results depict that UTS, yield strength and micro hardness values of composite fabricated with cylindrical left hand threaded pin tool were higher as compared to square tool pin profile. With increase in transverse speed UTS, micro hardness and yield strength increases and optimum value was obtained at transverse speed of $50 \mathrm{~mm} / \mathrm{min}$. From microstructure evaluation, reinforced particles were uniformly dispersed with left hand threaded tool at transverse speed of $50 \mathrm{~mm} / \mathrm{min}$ and fine grain size was obtained.
\end{abstract}

Keywords: Friction Stir Processing, Composite Material, AA6063/WC, Tool Pin Profile, Transverse Speed, Mechanical and Metallurgical Properties

\section{INTRODUCTION}

Friction stir processing (FSP) is a materials processing technique based on the principle of friction stir welding (FSW) process, where a non-consumable rotating tool having a shoulder and pin is plunged into the surface of a work piece and is moved forwarded in the direction perpendicular to the plunged and it was invited by The Welding Institute (TWI) of United Kingdom in 1991. There are several possible methods available which can be applied to a variety of material shapes and size. [1] A tool which is specially designed for the processing and it comprises of a pin and shoulder that have dimensions proportional to the sheet thickness. The pin of the rotating tool is plunged into the sheet material and the shoulder comes into contact with the surface of the sheet and then tool is moved in the desired direction. When the rotating tool comes in contact with the sheet, it generates heat which softens the material and material is softened below the melting point of the sheet. Due to the mechanical stirring action caused by the pin of the tool and the material, undergoes intense plastic deformation, within the processed zone yielding a dynamically-recrystallized fine grain microstructure. 


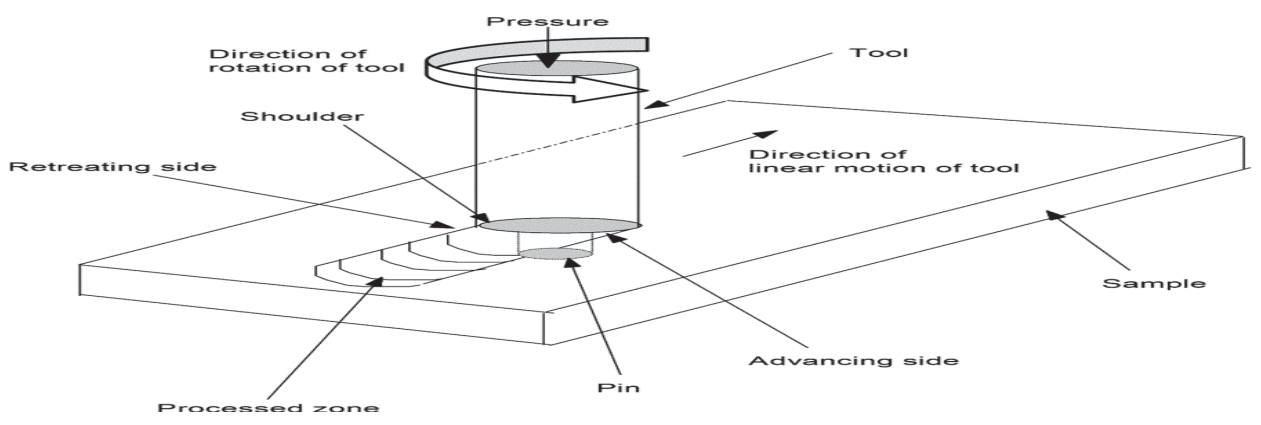

Fig.1 Schematic diagram of FSP process [1]

\section{LITERATURE REVIEW}

J Kwon et al. (2003) studied the effect tool travel rotational speed (900, 1300 and $1600 \mathrm{rpm})$ and concluded that with increase in rotational speed tensile and hardness increased. In this study 1050 aluminum alloy was used to enhance mechanical properties with the help of Friction Stir Processing. This results when these characteristics increased and grain refinement also goes up to $37 \%$ to $46 \%$ as compared to the starting material. Optimum result is obtained at $1300 \mathrm{rpm}$ [3]. P. Cavaliere (2006) observed the effect tool travel speed $(20 \mathrm{~mm} / \mathrm{min}, 40 \mathrm{~mm} / \mathrm{min}$ and 60 $\mathrm{mm} / \mathrm{min}$ ) and concluded that with increase in travel speed fine and stable grain structure is formed. Proposed the AM60B magnesium alloy with thickness $6 \mathrm{~mm}$ was successfully friction stir processed and the material exhibited improved room temperature tensile properties because of the consolidation of casting defects as a consequence of the stirring action. SEM observations showed a regime of grain boundary sliding in the regions of higher strain rate sensitivity calculated for the material in FSP condition [4]. B.M. Darras (2005) studied the effect of tool travel speed by the friction stir processing on the material composites and he found that the grain size becomes more homogeneous and the grain size in the nugget region is much smaller than the other regions. The heat affected zone was larger at $800 \mathrm{rpm}$ then the $600 \mathrm{rpm}$. The average grain size is reduced to about $1.67 \mu \mathrm{m}$ when FS processed at $600 \mathrm{rpm}$ and $2.5 \mathrm{in} / \mathrm{min}$. and to $4.49 \mu \mathrm{m}$ when FS processed at $1000 \mathrm{rpm}$ and $2.5 \mathrm{in} / \mathrm{min}$. In this process the hardness at the centre is more than the edges. The grain size produced is very fine upto $0.1-18$ micro meter. There is about $80 \%$ of the yield stress is achieved in the base metal [5]. M. Salehi et al. (2011) studied effect tool travel speed (20 $\mathrm{mm} / \mathrm{min}, 40 \mathrm{~mm} / \mathrm{min}$ and $60 \mathrm{~mm} / \mathrm{min}$ ) rotational speed $(900 \mathrm{rpm}, 1600 \mathrm{rpm}$ and $1900 \mathrm{rpm})$ and pin profile (cylindrical threaded and square tool pin) on AA6061/Sic nanocomposites produced by friction stir processing. The FSP process parameters were optimized to maximize the tensile strength of ASNCs. The optimum condition of the rotational speed, transverse speed, tool penetration depth, and pin profile were found to be $1600 \mathrm{r} / \mathrm{min}, 40 \mathrm{~mm} / \mathrm{min}$, $0.30 \mathrm{~mm}$ and threaded type respectively [6]. F. Khodabakhshi et al. (2014) observed that effect of tool travel speed ( $70 \mathrm{~mm} / \mathrm{min}, 85 \mathrm{~mm} / \mathrm{min}$ and $100 \mathrm{~mm} / \mathrm{min}$ ) on aluminum matrix nano composite were fabricated by friction stir processing of $\mathrm{Al}-\mathrm{Mg}$ alloy sheets with pre placed $\mathrm{TiO} 2$ particles caused in situ formation of $\mathrm{MgO}$ and $\mathrm{Al} 3 \mathrm{Ti}$ nanophases with an average size $50 \mathrm{~nm}$. The addition of $\mathrm{TiO}_{2}$ particles accelerated grain refinement of aluminum matrix during FSP [7]. M.K. Khraisheh et al. (2007) studied the effect the tool rotational speed (1200-2000 rpm) and transverse speed (20-30 in. / min) on AA6061/Sic by friction stir processing. The results of microstructure of FSP sample are more homogeneous than that of as-received material. It is clearly illustrated that FSP refined the microstructure from an average grain size about 6 . The results of the hardness clearly show that hardness of the processed sheets is extremely sensitive to the processing parameters [8]. A. Thangarasu et al. (2014) AA1050/Tic SMMC was fabricated using FSP. The fabricated AA1050/TiC composite layer was well-bonded to the aluminum substrate. TiC particles were distributed homogeneously in the FSP zone. The hardness of the FSP zone was increased by $45 \%$ higher than of the alloy. TiC particles enhanced the hardness of aluminum alloy. The average hardness of FSP zone is $45 \%$ higher as compare to base metal at $1200 \mathrm{rpm}$ and $60 \mathrm{~mm} / \mathrm{min}$ with axial force $10 \mathrm{KN}$ [9]. V. Yadav et al. (2014) studied the effect of reinforced particles on AL6082/Cu with thickness of plate $6 \mathrm{~mm}$. The UTS of the base metal (314 mpa) decreases after processing without composite (133-152 mpa). It was observed that the UTS of samples processed using cylindrical threaded tool profile $(152 \mathrm{mpa})$ is more than that of square profile (133 mpa) [10]. R. Sathiskumar et al. (2012) observed effect of parameters on microstructure and micro hardness of boron carbide particulate reinforced copper surface composites and they produced defect-free and sound surface composites with $40 \mathrm{~mm} / \mathrm{min}$. The parameters used were $20 \mathrm{~mm} / \mathrm{min}, 30 \mathrm{~mm} / \mathrm{min}, 40 \mathrm{~mm} / \mathrm{min}, 50 \mathrm{~mm} / \mathrm{min}$ and $60 \mathrm{~mm} / \mathrm{min}$ and rotational speed with 1000rpm, 1100rpm and $1200 \mathrm{rpm}$. The area of the surface composite 
increased when tool rotational speed was increased and reduced when processing speed was increased due to increase in frictional heat generation and the area of the surface composite reduced when groove width was increased. The distribution of $\mathrm{B}_{4} \mathrm{C}$ particles in the surface composites was influenced by tool and $132 \mathrm{Hv}$ at 1200 rpm [11]. Davidson et al. (2012) observed the effect of rotational speed on the micro structural changes and the mechanical properties of friction stir processed Mg AZ31B alloy sheets has been investigated. Friction Stir Process was carried out at rotational speeds in the range of 900 to $1400 \mathrm{rpm}$ with a constant traverse speed of $32 \mathrm{~mm} / \mathrm{min}$. The results show that the rotational speed has a significant effect on the microstructures as well as on the mechanical properties of the processed material and found that the optimal rotational speed gives highest mechanical properties [12]. D. Dharmpal et al. (2013) studied the effect of reinforced particles by using friction stir processing with $6 \mathrm{~mm}$ thick plate. Preparation of AL5083/sic surface composite by FSP and mechanical characterization. Present reveals that doping of $5083 \mathrm{Al}$ with hard sic particles through FSPleads to significant increase in hardness. The wear resistance of FSPed sample is inferior to that observed for 5083Al in spite of its higher hardness at $1200 \mathrm{rpm}$ and 40 $\mathrm{mm} / \mathrm{min}$ [13]. S. Jerome et al. (2012) studied the rotational speed on surface composite developed by single pass FSP with groove design, the average hardness along the top surface was found to increase by $22.72 \%$ as compared to that of the base metal whereas the in case of surface composite developed by double pass FSP in same and opposite direction, the average hardness along the top surface was found to increase by $25 \%$ and $27.27 \%$ respectively, as compared to that of the base metal. Parameters used are $1400 \mathrm{rpm}, 1120 \mathrm{rpm}$ and $900 \mathrm{rpm}$ with 6 $\mathrm{mm} / \mathrm{min}$ transverse speed. The maximum average depth of surface composite was found to be $250 \mu \mathrm{m}$ in holedesign. It is observed that with increasing rotational speed hardness also increases and optimum value is $108 \mathrm{hv}$ at 1400 rpm. [14]

\section{EXPERIMENTATION}

\section{Friction Stir Processing:}

The material under investigation was a AA6063 under the form of rolled plates of $5 \mathrm{~mm}$ thickness. Six specimens of size $200 \mathrm{~mm} \times 150 \mathrm{~mm}$ with holes $2 \mathrm{~mm}$ diameter and depth of $4 \mathrm{~mm}$ were processed to form composite AA6063/WC. Doping with tungsten carbide particles of size $5 \mu \mathrm{m}$. The employed tool rotational speeds of the cylindrical threaded tool and square tool pin was $1500 \mathrm{rpm}$ and transverse speed of $30 \mathrm{~mm} / \mathrm{min}, 40 \mathrm{~mm} / \mathrm{min}$ and 50 $\mathrm{mm} / \mathrm{min}$ respectively. A tool made up of High chromium high carbon steel with $20 \mathrm{~mm}$ tool shoulder diameter, 6 $\mathrm{mm}$ pin diameter and $4 \mathrm{~mm}$ long, shown in table 1, was used for present research work. Tool profile used in study is shown in Figure 2. The machine used for the fabrication of composite was fully automated vertical milling machine. Fixture was first fixed on the machine bed with help of clamps and then plates were held in the fixture properly for Friction Stir Processing.

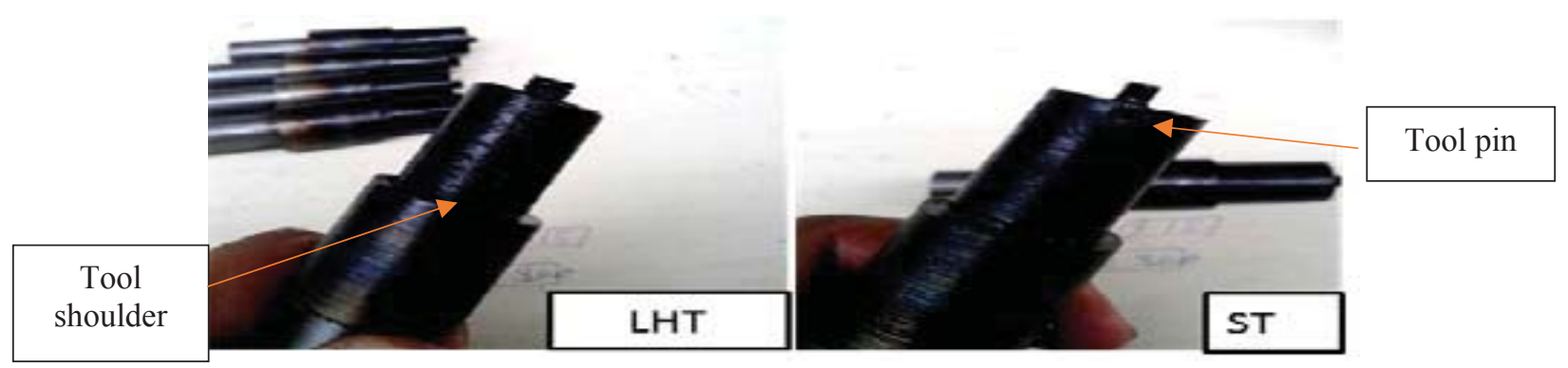

Fig 2 Tool used in research work 
Table 1 Tool description

\begin{tabular}{|c|c|c|}
\hline S.No & Description & Measurement \\
\hline 1 & Diameter of shoulder & $20 \mathrm{~mm}$ \\
\hline 3 & Length of tool pin & $4 \mathrm{~mm}$ \\
\hline 4 & $\begin{array}{c}\text { Diameter of cylindrical left } \\
\text { handed pin tool }\end{array}$ & $6 \mathrm{~mm}$ \\
\hline 5 & Pitch of thread & 1.5 \\
\hline 6 & Side of square pin tool & $4 \mathrm{~mm}$ \\
\hline
\end{tabular}

The specimens were prepared for friction stir processing as shown in fig 3

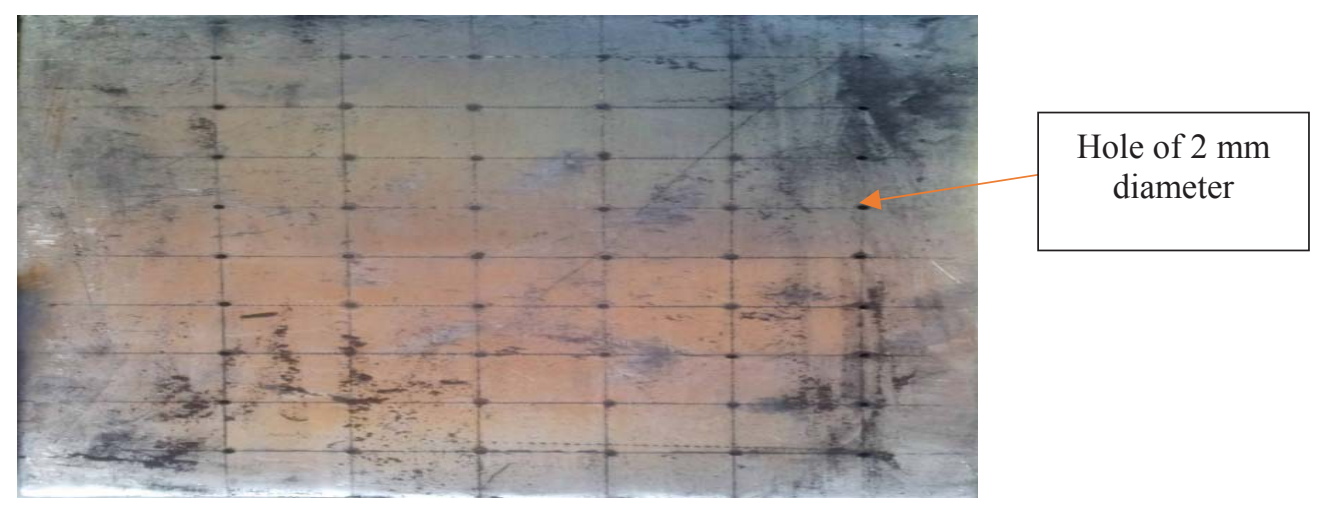

Fig 3 Prepared specimen for FSP

Table 2 shows the parameters used in final experiment. Six specimens were processed by friction stir processing and specimens were prepared for testing.

Table 2 Friction stir processing parameter used for final experimentation

\begin{tabular}{|c|c|c|}
\hline $\begin{array}{c}\text { Plate } \\
\text { No. }\end{array}$ & $\begin{array}{c}\text { Transverse Speed } \\
(\mathrm{mm} / \mathrm{min})\end{array}$ & Tool pin profile \\
\hline 1 & 30 & LHT \\
\hline 2 & 40 & LHT \\
\hline 3 & 50 & LHT \\
\hline 4 & 30 & ST \\
\hline 5 & 40 & ST \\
\hline 6 & 50 & ST \\
\hline
\end{tabular}

Tensile test specimens were prepared from the processed plate in accordance with ASTM specifications, E-8M-04, having specimen of $50 \mathrm{~mm}$ gauge length and $12.5 \mathrm{~mm}$ width. The load was applied until the necking was there and specimen failed. Servo Control Universal testing machine. Visual inspection was performed on all processed 
samples in order to verify the presence of macroscopic external defects such as surface irregularities, excessive flash, and lack of penetration, voids and surface open tunnel defects.

\section{EXPERIMENT AND RESULT}

A. Effect of tool pin profile and transverse speed on tensile strength of AA6063/WC composite fabricated: Tensile test results are shown in table 3 .

Table 3 tensile characteristics

\begin{tabular}{|c|c|c|c|c|}
\hline $\begin{array}{c}\text { Specimen } \\
\text { no }\end{array}$ & $\begin{array}{c}\text { Transverse } \\
\text { speed } \\
\text { (mm/min) }\end{array}$ & $\begin{array}{c}\text { Tool } \\
\text { used }\end{array}$ & $\begin{array}{c}\text { UTS } \\
\text { (Mpa) }\end{array}$ & $\begin{array}{c}\text { Yield } \\
\text { strength } \\
\text { (Mpa) }\end{array}$ \\
\hline S1 & 30 & LHT & 245 & 216 \\
\hline S2 & 40 & LHT & 248 & 221 \\
\hline S3 & 50 & LHT & 253 & 225 \\
\hline S4 & 30 & ST & 237 & 210 \\
\hline S5 & 40 & ST & 244 & 218 \\
\hline S6 & 50 & ST & 249 & 223 \\
\hline
\end{tabular}

UTS of fabricated composite was observed to be low at lower transverse speed and increases with increasing transverse speed from $30 \mathrm{~mm} / \mathrm{min}$ to $50 \mathrm{~mm} / \mathrm{min}$ as shown in figure 4 . Due to high heat input at transverse speed of $30 \mathrm{~mm} / \mathrm{min}$ as compare to transverse speed of $50 \mathrm{~mm} / \mathrm{min}$, there is grain growth and more coursing of grains in stir zone which is one of the reasons of lowering the UTS. Grain boundaries were the main obstacles to slip of dislocations and material have smaller grain size and hence higher UTS as it would impose more restrictions to dislocation movement. With increase in transverse speed the interaction between tool and work piece is improved and sufficient frictional heat generation per unit length causes better plastic flow of material at SZ which leads to higher UTS value at feed speed of $50 \mathrm{~mm} / \mathrm{min}$. [4]

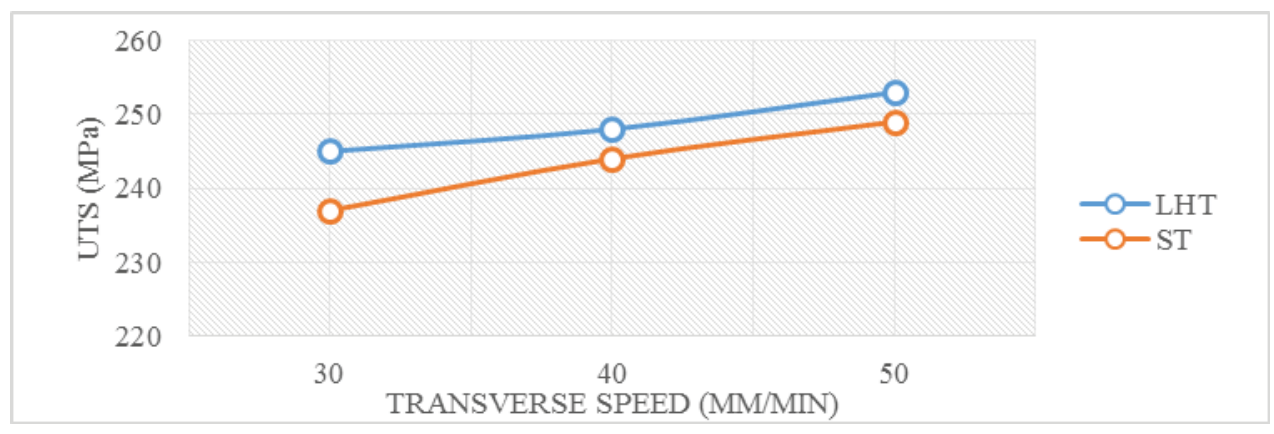

Fig 4 effect of transverse speed and tool pin profile on tensile strength

In case of cylindrical tool pin profile with Left hand threaded the material flow is horizontal as well as vertical inclined from top to bottom surface which will fill the bottom cavity at bottom of pin. But in case of square tool pin surface area is more due to which more heat is generated. High heat is responsible for grain growth and coarse grain size is obtained. [10]. By using the reinforced tungsten carbide particles tensile strength increases as compare to base metal (241 MPa). During FSP reinforced particles break grains of base metal and prevent the grain growth by precipitate on outer boundary of grains of base metal and hence fine grains are obtained. [15]

\section{B. Effect of transverse speed and tool pin profile and on yield strength of AA6063/WC composite:}

As observed from Figures 5, the yield strength of fabricated composite was observed to be low at lower transverse speed and increases with increasing transverse speed from $30 \mathrm{~mm} / \mathrm{min}$ to $50 \mathrm{~mm} / \mathrm{min}$. The low transverse speed of 30 $\mathrm{mm} / \mathrm{min}$ is associated with high heat generation as compare to transverse speed of $50 \mathrm{~mm} / \mathrm{min}$. High heat input 
creates coarse grains in stir zone which is one of the reasons of lowering the yield strength at processing speed of 30 $\mathrm{mm} / \mathrm{min}$. [4]

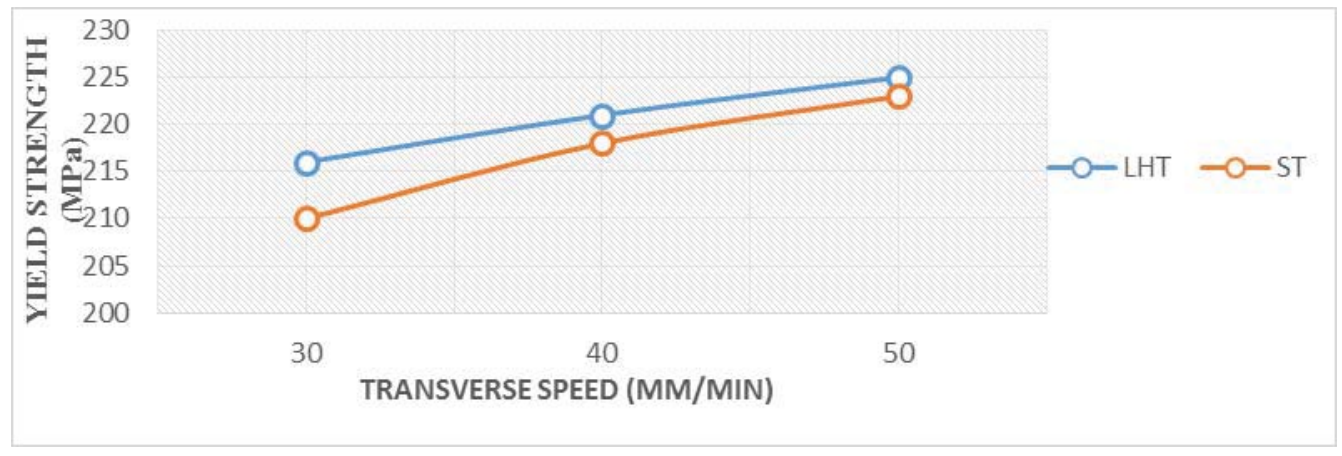

Fig 5 Effect of transverse speed and tool pin profile on yield strength

In case of cylindrical tool pin profile with Left hand threaded the material flow is horizontal as well as vertical inclined from top to bottom surface which will fill the bottom cavity at bottom of pin. But in case of square tool pin surface area is more due to which more heat is generated. High heat is responsible for grain growth and coarse grain size is obtained. [10]. By using the reinforced tungsten carbide particles yield strength is more as compare to base metal. During FSP reinforced particles break grains of base metal and prevent the grain growth by precipitate on outer boundary of gains of base metal and hence fine grains are obtained. [15]

\section{Effect of transverse speed and tool pin profile on micro hardness of AA6063/WC composite fabricated:}

The Vickers hardness profile of the processed specimens was measured at a distance $2.5 \mathrm{~mm}$ from the top surface of the specimen thickness on a cross-section perpendicular to the processed direction using Vickers hardness tester with 200 gf loads for 10 seconds. Micro hardness of 6063 is $83 \mathrm{Hv}$. Micro hardness results shown in table 4:

Table 4 Micro hardness results

\begin{tabular}{|c|c|c|c|}
\hline $\begin{array}{l}\text { Speci } \\
\text { men } \\
\text { no }\end{array}$ & $\begin{array}{l}\text { Transverse } \\
\text { speed } \\
(\mathrm{mm} / \mathrm{min})\end{array}$ & $\begin{array}{l}\text { Tool } \\
\text { used }\end{array}$ & $\begin{array}{l}\text { Micro } \\
\text { hardness } \\
(\mathrm{Hv})\end{array}$ \\
\hline S1 & 30 & LHT & 135 \\
\hline S2 & 40 & LHT & 151 \\
\hline S3 & 50 & LHT & 163 \\
\hline S4 & 30 & ST & 215 \\
\hline S5 & 40 & ST & 142 \\
\hline S6 & 50 & ST & 155 \\
\hline
\end{tabular}

It is concluded that the micro hardness value is more with $50 \mathrm{~mm} / \mathrm{min}$ as compare to $30 \mathrm{~mm} / \mathrm{min}$ processing speed at constant tool rotational speed of $1500 \mathrm{rpm}$ with LHT. Low transverse speed is associated with high heat in processed which decreases the cooling rate which further produces coarse grain. Increase transverse speed grain sizes are reduced because of sufficient heat produced. Also Micro hardness is a function of grain size i.e. smaller the grain size higher will be the micro hardness value. The grain boundaries become the main obstacle to the slip of dislocations and the material with smaller grain size would have higher micro hardness or tensile strength as it would impose restriction to the dislocation movement. [4] 


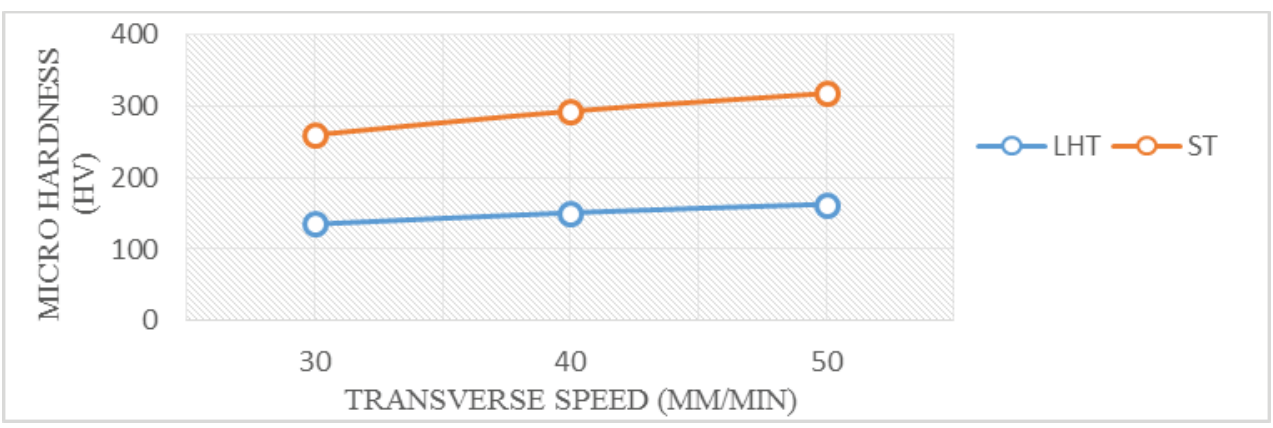

Fig 6 Effect of transverse speed and tool pin profile on micro hardness

The hardness is more with cylindrical left hand threaded tool as compare to square tool pin. The reason to this can be attributed the whirling effect of threads of LHT which is absent in square tool. In square tool pin more area covered and high heat production result in coarse grains and hence coarse grain size result in less hardness [10]. Base metal has hardness value $83 \mathrm{hv}$ but with addition of tungsten carbide particles increases the hardness. By addition of tungsten carbide particles breaks the grains of base metal and precipitate on grain boundaries avoid grain growth hence fine grain size was achieved and hence more hardness value because hardness is function of grain size. Optimum value of hardness $163 \mathrm{HV}$ obtained at $50 \mathrm{~mm} / \mathrm{min}$ with LHT. [15]

\section{Microstructure Evaluation:}


Fig 7 Microstructure of left hand threaded pin tool profile
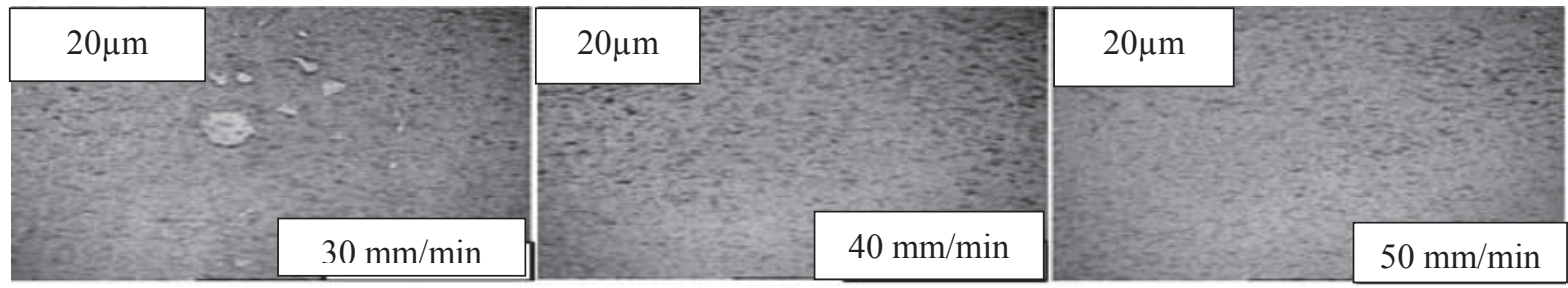

Fig 8 Microstructure of square pin tool profile

Microstructure at $50 \mathrm{~mm} / \mathrm{min}$ shows uniform dispersion of tungsten carbide particles and fine grain structure. This is due to heat effect because at high transverse speed sufficient heat is produced. This heat is enough to break the grains of material and uniformly dispersion of reinforced particles and fine grain structure is obtained. But in case of 30 $\mathrm{mm} / \mathrm{min}$ high heat produced results in grain growth and coarse grains are obtained which lower the UTS, yield strength and hardness. Increase in transverse speed up to $40 \mathrm{~mm} / \mathrm{min}$, there is better grain refinement but not as good as in $50 \mathrm{~mm} / \mathrm{min}$ [4]. Microstructure with left hand threaded tool at $50 \mathrm{~mm} / \mathrm{min}$ shows uniformly dispersion of reinforced particles. This is because of flow pattern that's vertical and horizontal. In case of square tool pin, it has more surface area therefore WC particles in microstructure are not uniformly dispersed and are distributed in wider area of specimen. With using left handed threaded tool flow of material is in both direction of horizontal and vertical result in uniform dispersion of reinforced particles. In taper tool only flow in one direction which lower UTS, yield strength and hardness as compare to LHT. In square tool pin more area under processed and hence wider dispersion of reinforced particles. [10] 


\section{V.CONCLUSION}

- The Tensile strength, Yield strength and micro hardness are the properties which were significantly affected by tool transverse speed, tool pin profile and tungsten carbide particles.

- Tensile strength, yield strength and hardness have optimum value with cylindrical left hand threaded tool at 50 $\mathrm{mm} / \mathrm{min}$

- Tensile Strength, Yield strength and micro hardness are increases with the increase of transverse speed from 30 $\mathrm{mm} / \mathrm{min}$ to $50 \mathrm{~mm} / \mathrm{min}$.

- Homogenous dispersion of reinforced particles is achieved at $50 \mathrm{~mm} / \mathrm{min}, 1500 \mathrm{rpm}$ with cylindrical left handed threaded tool.

- Tensile strength, yield strength and micro hardness are increased with doping of tungsten carbide reinforced particles.

\section{REFERENCES}

[1] Mishra R.S., Ma Z.Y, Cha, I., (2003) "Friction stir processing: a novel technique for fabrication of surface Composite", J. Materials Science and Engineering vol. 341, 2003, pp 307-310.

[2] Santella M L, Engstrom T., Torjoham D.S, Pan T-Y, "Effects of Friction Stir Process (FSP) on mechanical properties of cast aluminium alloys A319 and A356” Journals of Material Processing Technology, vol. 53, 2, 2005, pp 201-206.

[3] Kwon Y.J., Shigematsu I, Saito N. (2003), "Mechanical Properties of aluminum alloy by the method of Friction Stir Process" ScriptaMaterial, vol. 49, 8, 2003, pp 785-789

[4] Cavaliere P. (2013), "Burnishing effects on friction stir Processing of Al alloy 7075-T6" Global journal of researches in engineering, vol. 14, 3, version 1.0, 2014, pp 13-20.

[5] Darras Basil Ma. (2014), "Fatigue life improvement by friction stir processing of 5083 aluminum alloy Mig butt weld" Theoretical and applied fracture mechanics,vol. 13, 2014, pp 1-7.

[6] Salehi M., M.Saadatmand, J.Aghazadeh mohandesi (2009) "Optimization of process parameters for producing AA6063/SiC nanocomposite by friction stir processing" ELSEVIER science direct vol.13, 2009, pp 1055-1063.

[7] L. hodabakhshi F, A.Simchi,A.H.Kokabi, F.Simancik,P.Svec(2013), "Microstructure and texture development during friction stir processing of $\mathrm{AL}-\mathrm{MG}$ alloy sheets with $\mathrm{TiO}_{2}$ "material science and engineering vol. 605, 2014, pp 108-118.

[8] Darras B.M., Khraisheh M.K., Abu-Farha F.K., Omar M.A. (2007), "Friction Stir Processing has emerged as an effective tool for enhancing sheet metal properties through microstructure modification” Journals of Material Processing Technology, vol. 191, 3, 2007, pp $77-81$.

[9] Thangarasu A., N.Murugan,I.Dinaharam (2014) "Production and wear characterization of AA6082-TiC surface composite by friction stir processing" science direct procedia engineering vol 97, 2014, pp 590-597

[10] Yadav Vikrant, Kumar Vinay, Tiwari Vataslya (2014) "Effect of pin profile on mechanical propreties of AL6082 and AL6082-Cu composite by friction stir processing"IOSR journal of mechanical and civil engineering vol. 11, 3, 2014, pp 07-11.

[11] R Sathiskumar "FSP of aluminum cast alloys for high performance applications" Springer, vol. 63, 11, 2011, pp 44-50.

[12] Davidson, Tagore M.J. (2012), "Effect of rotational speed on the microstructural changes and mechanical properties of friction stir processed Mg AZ31B” Advanced in Engineering Science and Management, vol. 5, 2012, pp 323-327.

[13] Deepak Dharmpal, singh ripandeep, Gupta V.K (2013), "Preparation of 5083 Al-sic surface composite by FSP and its mechanical characterization", international journal vol. 3, 1, 2013, pp 12-17.

[14] Jerome S., Govind S., Kumaresh babu S.P., Ravisankar B. (2012) "Influence of microstructure and experimental parameter on mechanical and wear propreties of Al-TiC surface composite by FSP" journal of mineral and materials characterization and engineering vol. 11, 5, 2012, pp 493-507.

[15] Rao pydi Hari parasada (2013), "Microstructure exploration of aluminum-tungsten carbide composite with different manufacturing circumstances" international journal of soft computing and engineering vol. 2, 6, 2013, pp 33-45. 